\title{
Language learner motivation and the role of choice in ESP listening engagement
}

David N. Brown

\section{(2) OpenEdition}

1 Journals

Electronic version

URL: http://journals.openedition.org/asp/579

DOI: $10.4000 / a s p .579$

ISBN: 978-2-8218-0404-3

ISSN: 2108-6354

Publisher

Groupe d'étude et de recherche en anglais de spécialité

Printed version

Date of publication: 1 December 2007

Number of pages: 159-177

ISSN: 1246-8185

Electronic reference

David N. Brown, "Language learner motivation and the role of choice in ESP listening engagement", ASp [Online], 51-52 | 2007, Online since 01 December 2010, connection on 22 March 2021. URL: http:// journals.openedition.org/asp/579; DOI: https://doi.org/10.4000/asp.579

This text was automatically generated on 22 March 2021.

Tous droits réservés 


\title{
Language learner motivation and the role of choice in ESP listening engagement
}

\author{
David N. Brown
}

\section{Introduction}

1 A desire to cultivate in learners a favourable predisposition to the learning of a foreign language might be taken as an acceptable summing-up of the role of language instructors. Such a predisposition could be characterised as the proficiency to monitor one's behaviour and attitudes, to deploy appropriate strategies, to modify such strategies when task demands shift in focus and to participate as responsible, independent and active learners in one's own learning process. In other words, when that objective is reached, the resulting language learner is motivated and self-regulated (Zimmerman 1990).

2 At the same time, within the profession of language teaching for specific purposes, there is frequently the feeling that language syllabuses are more motivating for learners when they are oriented towards the specialisations of the students concerned. Thus, students of medicine will study a foreign language via exposure to medical or pseudo-medical materials, engineering students will be exposed to engineering or pseudo-engineering materials and life-science students will be exposed to life science or pseudo-life-science materials. The rationale behind such an approach is that familiarising learners with the discourse types of their future profession is beneficial for them. A specific range of vocabulary and a streamlined version of the grammar, all placed within ostensibly appropriate discourse is, consequently, targeted. But documentary proof substantiating the success of the approach is lacking. Certitudes about its validity seem to stem from a language-teacher lore that students are most at home with themes linked to their future careers, or from evidence gathered in contexts different from those generally encountered in the area of teaching English to learners 
specialising in other disciplines in France. Such certitudes tend not to stem from specifically designed studies that compare performance data and results gathered within the French context. Indeed, there does not seem to be much data that measures the success or failure of such objectives. In addition, it is not clear whether the learning of specialised vocabulary and the mastery of a specific type of discourse give birth to a motivated and self-regulated learner. Such an approach may in fact merely result in "teaching to test", that is to say teaching only the comparatively narrow battery of facts required for examination purposes as opposed to exposure to the relatively broad input of linguistic and metalinguistic knowledge necessary for threshold communicative fluency.

3 A third factor is that of choice. It is widely accepted that choice plays an important role in intrinsic motivation (Stipek 1997). Kohn (1993: 14) underlines the importance of choice and how it enhances, among other things, activity level, enthusiasm, depth of learning, rate of learning and self-regulation. Choice is taken even to an ideological level, opposing Western democratic society with that of Eastern pyramidal society, or even socialism. ${ }^{1}$ Between these two extremes is a spectrum of conditions ranging from what might be classified as the staunchly individualistic (essentially Anglo-Saxon) to the patriarchal collectivistic (essentially Oriental). A convincing discussion put forward by Triandis (1990) leads one to the unavoidable conclusion that France should not be included among the individualistic nations. Others, namely Buss (1990), Hofstede and Bond (1984), Pettigrew (1988) and Triandis et al. (1986), support and exemplify Triandis's (1990) reasoning from the point of view of varying cultural traits. Indeed, Brown (2002) uncovered unexpected behaviour among French engineering students who were being observed in choice / limited-choice language-learning environments. In this comparative study, it transpired that greater intrinsic motivation and learner performance were displayed in situations where personal choice had been curtailed, and where the choices made for the participants were determined by a meaningful and significant (and even anonymous) other: someone who could claim to be, at least to a certain extent, a specialist in the area at issue. Usually, behaviour such as this is associated with learners of Oriental origin. So, even though intuitive appeal and past research have generated the belief that the provision of individual choice, whether this be de facto or merely on the perceptual level, will nurture intrinsically motivated behaviour patterns, Brown's findings cast a shadow over this belief. They reveal that more desirable results may sometimes be harvested from situations in which choice is channelled or limited in some way. Indeed, as Iyengar and Lepper (1999) have shown, the desire to exert choice seems to be conditioned by the culture of the individuals concerned. Consequently, the standpoint that French learners of a foreign language may be demotivated by choice (and bearing in mind the different studies described earlier, the idea that France constitutes a collectivistic, albeit moderately collectivistic, nation goes hand in hand with this suggestion) is not an unreasonable one.

It seems then for cultural reasons and for reasons to do with reflexes brought into existence essentially during the secondary-school years that choice is not as critical for French learners as some may believe. There are sufficient numbers of oral accounts and anecdotal reports of experiments in self-directed learning in French university language departments not having fulfilled expectations to bear this out. Also, this may explain the emergence of the hybrid off-shoot contradictorily labelled "guided autonomy" (a convenient device that bridles the drift away from collectivism and control while remaining loyal to present mainstream pedagogical beliefs). In brief, 
within the context of French culture, group-belonging and the concomitant harmony therein still seem to be deeply rooted characteristics, while French educational methodology (an obvious direct consequence of the culture) reinforces this behaviour: Lieury and Fenouillet (1997: 134) speak of "the expectation of assigned tasks, and the approbation from and dependence on teachers. All of which combine to reduce intrinsic motivation at school." And beyond school into university, one is tempted to add.

5 So is there a place for choice and, when left to choose, will learners involved in vocational curricula automatically lean towards vocational language-learning content? Also, what of the nature of motivation within such learning contexts? The idea of the individual acting under his own direction and benefiting as a learner is a supremely potent one that, as we have seen, has permeated foreign language learning theory in France. But the idea, in spite of its natural appeal, seems to be in every sense of the word a foreign one. Initially, the concept stems from Anglo-Saxon, or more specifically North American, thought on education. And therein lies the conundrum; the wholesale transferability of an essentially individualistic concept to a socio-cultural context beyond that from which it stems may not be genuinely possible. Can such a concept be suited to learning tradition in a country like France, which remains teacher-centred and authority-oriented? And is there a negotiated version appropriate to French learning behaviour?

6 The concepts of choice and intrinsic motivation in learning are traditionally perceived to be inherently linked. This is particularly illustrated by work carried out in the area of self-determination. According to self-determination theory (see especially Deci 1992 and Deci, Vallerand, Pelletier \& Ryan 1991), cognitive and affective engagement are increased when learner choice is present, thus resulting in a knock-on effect on intrinsic motivation. Field research in the area (see Miserandino 1996) tends to support the idea that teacher-controlled environments in formal classroom settings will invariably undermine individual autonomy and intrinsic motivation and bring about a decrease in learning and an increase in negative attitudes. It seems that all researchers in the area concur as to the positive effects (even if only perceived) of autonomy on intrinsic motivation and attitudes. Another area, that of reader response theory, also positively associates the concept of choice to both short-term interest (Deci 1992, Hynds 1990) and cognitive processing (Gambrell \& Marinak 1997). Evidence that directly contradicts the benefits of learner choice is apparently rare and is usually to be found in non-individualistic environments (see, for example, Richardson 2004: Maynard 2003: 2 for more insight into Arab learners; Subramaniam 2006 for Malaysian learners, or Liu 2005: 47-48, for Chinese learners).

7 To our knowledge, no direct research on the relationship between choice and listening exists, whether this is in the general field of motivational psychology or within the more restricted area, closer to home, of foreign language acquisition. This begs a certain number of questions. First, is the positive relationship between affective engagement (intrinsic motivation, feeling of satisfaction and reduced anxiety) and choice operative when the language learner is in the process of listening? Second, is there a positive relationship during listening between choice and cognitive engagement (better strategy, capacity for recall, increased mastery and improved skills)? Third, is there a relationship between language-learner performance and choice 
(Wise 1994) in so far as the latter may reduce anxiety, which in turn may increase the former?

\section{The study}

Observation over a period of many years has led to the present writer's belief that a certain amount of misunderstanding has been generated by some of the reports on selfdirected learning experiences involving university undergraduates. Closer scrutiny reveals that many attempts to transform students into autonomous learners of English may not have been as successful as it was initially assumed. The problem is perhaps one of degree or focus: what is the benchmark of success? The primary objective of the present research was to clarify whether listening-type choice has positive impacts on (i) affective engagement and (ii) cognitive engagement. An auxiliary objective was to determine the validity of the folk-assumption that English language learners specialising in other disciplines are more motivated when foreign language ( $\mathrm{FL}$ ) learning (in the present case listening) activities are based on a languages-for-specificpurposes approach. A third, and minor objective from our point of view was to examine the possible broad implications for autonomous and self-directed language learning for students specialising in other disciplines.

The extent to which choice in listening influences the types of engagement mentioned above (affective and cognitive) must necessarily be linked to theories about autonomous learning. If such theories are accurate then one would expect increased engagement of at least one of the two types, as well as, although possibly to a lesser extent, better performance within groups of learners who have exercised choice in language learning situations. On the other hand, an absence of increased engagement and performance would constitute a contradiction to claims that vocationally-oriented materials are desirable for science students. Also, the place of self-directed learning within certain institutional environments would be brought into question. The strong folk element that governs choices of both teaching methodology and syllabus content may have led to a somewhat fogged view of what constitutes success as measured by performance and student perceptions of satisfaction in institutional foreign-language learning. It is not clear whether engagement is increased and, if it is, by how much.

\section{The method}

The study involved engineering students ( $\mathrm{N}=159$ initially) in their first year at the engineering college ESSTIN (École Supérieure des Sciences et Techniques de l'Ingénieur de Nancy). The participants, aged 18 or 19 years old, were drawn from 14 language groups each made up of a maximum of 12 learners. A particular effort was made to distribute the learners evenly across three groups: an unlimited-choice group (UCG), a no-choice group (NCG) and a control group (CG). In other words, a balanced number of strong, intermediate and weak learners was channelled into each group in order to provide three homogeneous sets. Thus, the UCG was made up of 88 students; the NCG and the CG were composed respectively of 37 and 34 students. The experiment was undertaken on a Friday during the second of two weekly language lessons ( $2 \times 2$ hours per week). This paper reports only on data drawn from that particular experiment even though similar studies were carried out with students of medicine and life sciences. ${ }^{2}$ 
11 The implements for data collection included three four-minute listenings per category of student, one true-false exercise composed of twenty items per listening, one choice sheet and a battery of questionnaires (see appendices).

\section{Data collection}

\subsection{The listenings and the true-false exercises}

12 The listening themes for the UCG students were as follows:

- within the theme of engineering, a 4 min. 40 s (589 words) listening on bridge building.

- within the theme of current affairs, a $4 \mathrm{~min}$. (570 words) listening on the future role of universities.

- within the theme of literature, 4 mn. (590 words) listening on the life of the Amish.

13 Although there are minor variations in length, the three listenings were considered of equivalent listening difficulty: the sound quality and the speaker were identical in each listening, the delivery measured in words per minute relatively similar, the grammar had previously been covered within a grammar revision module studied by all the students concerned during the first six weeks of class, and over $90 \%$ of the vocabulary content was to be found in the vocabulary lists and worksheets used in class. These factors were unimportant during the choice phase, but it was initially felt that they could have influenced the evaluation of performance. As it happened, these were needless precautions bearing in mind that evaluation of performance concerned only the most frequently chosen listening. In other words, no comparison between listenings (and by that token between arguably differing vocabulary content or grammatical complexity) was made.

\subsection{The choice sheet (appendix 1)}

14 The choice sheet was both a means to allow the students to materialise their choice of listening and a method for the administrators of the experiment to keep track of the number of times each listening had been selected and to verify that the students went to the room that effectively corresponded to their choice of listening. On the sheet, an A5-sized docket, the participants were asked to choose one of the three listenings on the basis of three one-sentence descriptors labelled A, B and C. Beneath each descriptor appeared the room they were to go to for their particular choice.

\subsection{The questionnaires (appendix 2)}

The first questionnaire (appendix 2a), entitled "Croyances et comportements face aux devoirs et tests" for the purposes of this paper, is made up of 13 statements. It is a retailored version of the "Desire for Control" questionnaire initially developed by Wise et al. (1996: 34) over three separate experiments. It measures the degree of control desired by individuals in a testing situation. This is the only questionnaire that was filled in prior to the listening stage. The other three questionnaires were completed after the listening exercise had taken place. was retailored from work carried out by Schraw et al. (1995). It is composed of ten 
statements plus an open question inviting students to suggest the listening theme they would have chosen had they had the option of full and unlimited choice.

of the two types of engagement that were measured during the experiment, affective measurement was simplified by means of a 12-itemed attitudes questionnaire ("Attitudes pendant les activités d'écoute" - appendix 2c) inspired by work done by Kohn (1993).

It was cognitive measurement that proved to be the greatest source of difficulty. The 10-itemed questionnaire ("Engagement cognitif pendant les activités d'écoute" - appendix 2d) was developed using the well-honed procedure called "retroactive verbal reporting." This lengthy process involved testing the experimental listenings on a separate group of students (forty third-year students), in order to gauge their reactions via a report written after listening. They were asked to express their thoughts on two separate points: their interpretation of the information and the feelings generated during listening. The students' writings were subsequently examined and their reactions were used to compose the ten statements of the questionnaire around the categories (namely strategy, recall, mastery and overall skills) mentioned earlier in this article.

All of the questionnaires were rated on a five-point Likert scale ranging from "pas $d u$ tout d'accord" (1) to "tout à fait d'accord" (5). As regards the three questionnaires that were completed after the listening stage, it was felt that the order in which they were completed was of no importance.

\section{The procedure}

\subsection{The Unlimited-choice Group (UCG)}

The experiment was made up of two phases: one in a lecture hall and the second in an ordinary classroom. Two weeks before a scheduled English exam that was to include a heavily-weighted listening component, an initial group of 88 students were asked to meet in a lecture hall instead of going to their usual classroom. They had received no prior warning of this change to their Friday-morning timetable. The pretexts given for the change were (i) the head of the language department wanted the learners to gauge how prepared they were for the listening test so they could decide how much time they would need to dedicate to revision and (ii) to give them the opportunity to gain experience of the exam format and conditions. It was explained to the learners that they would hear a listening passage just one time. Next, the students were told that contrary to custom, they would select the thematic content of the listening test. The "choice sheet" (appendix 1) was then distributed and duly filled in. Finally, to complete phase one, the students were asked to complete the first of the four questionnaires ("Croyances et comportements face aux devoirs et tests" - appendix 2a). They were advised that three others would follow the listening activity. They were then allowed to disperse to their selected rooms. All of this information was given in French.

Phase two took place in the classrooms designated for each listening. On arrival at their destination, the teacher checked each choice sheet to ensure that the student was in the right room. Once students had settled down, the teacher distributed the exercise corresponding to the listening and, having allowed the students two minutes to preread the exercise, played the passage once. At the end of the listening, the answer 
sheets were handed in and the first of the remaining questionnaires distributed. Each following questionnaire was distributed once the preceding one had been retrieved. The order of distribution was not considered of importance. While the students were filling in the questionnaires, the teacher checked the A-to-F grid that appears at the top of each sheet. This grid subsequently permitted accurate identification of listening choice (where appropriate) and of group membership.

\subsection{The No-choice Group (NCG)}

The No-choice Group met later the same day. The procedure for the NCG students ( $\mathrm{N}=$ 34) differed only in that the theme was assigned. Consequently, the choice-sheet was not needed. The NCG students were, nevertheless, shown a projected copy of the choice-sheet and they were told that the UCG participants had completed it. The NCG students were advised that they were being asked to do the listening because an insufficient number of students in the previous group had chosen it. This ploy was used merely to make the students aware that they had been deprived of choice while other students had not. In reality, nothing could have been further from the truth as the theme retained for the latter stages of the experiment was the one that had been selected by the majority of UCG students.

\subsection{The Control Group (CG)}

Differences with the two previous situations were minor. The theme assigned to the CG students $(\mathrm{N}=35)$ was the same as the one assigned to the NCG students. The CG students were simply asked to do a pre-exam listening to gauge how prepared they were for the forthcoming test. They were told nothing about the experiment or the fact that other groups of students had done the listening exercise. Neither were they shown the choice sheet. The CG students were, however, asked to fill in the questionnaires. No explanations as to why they were being asked to do so were offered.

It is customary to include a control group in such studies. Also, in this particular instance, it was hypothesized that the control group could serve to measure the comparative effects that choice had on listening engagement. In the eventuality that a comparison between the UCG and the ECG reveals no difference, one may be uncovered with respect to the CG. This would imply that choice results in zero impact on engagement, while absence of choice results in negative impact. Alternatively, the UCG could differ from the other two. The implication in this case is that choice has positive impact on engagement, while lack of choice would constitute negative impact. A final scenario would be one that revealed the groups to be radically different from each other. In this case, one would have to conclude that both choice and its absence influence engagement.

\section{The results}

25 A one-way, between-subjects analysis of variance (ANOVA) was used to compile the results obtained from the three groups. Only the data from the current affairs listening were used in the statistical analysis because it was selected more frequently $(\mathrm{N}=37)$ than the two others. Furthermore, in view of the design of the experiment, it was felt 
that a comparison between unlike components would have been inappropriate. Indeed, no design contingency had been included to cater for such a comparison. Consequently, students who selected the engineering theme $(\mathrm{N}=21)$ and the literature theme $(\mathrm{N}=25)$ were dropped from the analysis. A small number of responses $(\mathrm{N}=5)$ were removed from the study; it was impossible to identify their choice because the grid had been incorrectly completed. Consequently, the results that follow are harvested from data concerning 106 students.

The questionnaires were analysed separately, the statistical tests being carried out at the $p<0.01$ levels. The scores from the 5-point Likert scale from each individual questionnaire were added up to produce a single composite score per student for each of the four questionnaires. Hence, the minimum score per questionnaire was 0 , while the maximum was $\mathrm{N} \times 5, \mathrm{~N}$ being the number of statements in any given questionnaire.

\subsection{Performance}

Mainstream intrinsic motivation / choice theory assumes that choice should lead to improved performance. In this experiment, the students' performance, as measured on the $\mathrm{T} / \mathrm{F}$ listening activity, does not point to that conclusion. Comparison of results drawn from the sample seems to indicate that performance between groups does not vary significantly whether the choice is clearly allotted, openly denied or merely not invoked (as in cases where the learners received no particular information concerning the activity). Although the NCG average is marginally better than that of the two other groups, this cannot be taken as sufficient proof that denial of choice leads to improved performance (Table 1). The forthcoming analysis of the remaining groups may shed more light on this issue. Of course, it could be argued that the type of improved performance that really counts is that which is obtained over long periods. And it may be hypothesised that a captive audience (typically the type found in learning contexts similar to ESSTIN's) will not yield improved performance, while voluntary learners will invariably acquire better performance over time. There seems to be no solid evidence in favour of either postulate and the design of this experiment does not cater for that question.

Table 1. Performance averages between groups

\begin{tabular}{|l|l|l|l|}
\hline & UCG & NCG & ECG \\
\hline Engineering & 11.40 & 11.42 & 11.35 \\
\hline
\end{tabular}

AVERAgE SCORE OUT OF 20 ON THE LISTENINg EXERCISE PER gROUP

\subsection{Desire for control}

Choice, or lack of it, may have no noticeable effect on performance. Desire for control, however, may have an effect depending on whether the context is a choice-allotted one as opposed to a choice-denied one. One argument is that learners wish to control their own outcomes and, consequently, do better when they are permitted to take the reins. But some learners seem to prefer a submissive role, or simply have no preference at all. 
The learners in this sample were asked to respond on a 1 to 5 Likert scale to a desire for control questionnaire: "Beliefs and behaviour during listening activities". A choice $\mathrm{x}$ no-choice ANOVA of their responses revealed an absence of notable effects for any category (means: $\mathrm{UCG}=45.000, \mathrm{NCG}=47.857, \mathrm{CG}=45.971$ ): $F=1.40, p=0.2522$. Tukey comparisons confirm the absence of statistical significance in these findings. Consequently, and in spite of established beliefs, neither choice attribution, nor choice denial seem to have had influence on learner behaviour in this particular case.

\subsection{Affective engagement}

Affective engagement was analysed via two 5-point Likert questionnaires (one designated "Attitudes during listening" and the other designated "Perceived interest during listening") that the students completed after listening. From the point of view of self-perceived attitudes, the UCG displays by far the highest degree of affective engagement (a mean of 37.595 - Table 2). The NCG comes in a somewhat distant third. A choice $\mathrm{x}$ no-choice ANOVA of student responses to the questionnaire "Attitudes during listening" yielded significant statistical effects for the unlimited-choice category (UCG): $F=26.32, p=0.0001$. Tukey comparisons confirm the statistical significance of these findings (Table 2).

Table 2. Affective engagement (attitudes)

\begin{tabular}{|c|c|c|c|c|c|c|c|}
\hline Score by Group & $\mathbf{N}$ & \multicolumn{3}{|c|}{ Mean } & \multicolumn{2}{|l|}{ SD } & SE \\
\hline UCG & 37 & \multicolumn{3}{|c|}{37.595} & \multicolumn{2}{|c|}{8.170} & 1.3431 \\
\hline NCG & 35 & \multicolumn{3}{|c|}{26.286} & \multicolumn{2}{|c|}{6.837} & 1.1556 \\
\hline CG & 34 & \multicolumn{2}{|c|}{28.000} & & \multicolumn{2}{|c|}{6.199} & 1.0631 \\
\hline Source of variation & SSq & \multicolumn{2}{|l|}{ DF } & MSq & & $\mathbf{F}$ & p \\
\hline Between groups & 2687.948 & \multicolumn{2}{|l|}{2} & 1343.9 & 974 & 26.32 & 0.0001 \\
\hline Within groups & 5260.062 & \multicolumn{2}{|c|}{103} & \multicolumn{2}{|l|}{51.069} & & \\
\hline Total & 7948.009 & 105 & & & & & \\
\hline Contrast & \multicolumn{2}{|l|}{ Difference } & \multicolumn{3}{|l|}{ Tukey 95\% CI } & & \\
\hline UCG v NCG & 11.309 & & 7.302 to 15.316 & & & & nificant) \\
\hline UCG v CG & 9.595 & & 5.557 to 13.632 & & & & nificant) \\
\hline NCG v CG & -1.714 & & -5.806 to 2.378 & & & & \\
\hline
\end{tabular}

1-way between subjects ANOVA $(n=106)$ Attitudes during listening 
As for the other questionnaire ("Perceived interest during listening"), the results are fairly similar in that once again UCG displays the highest degree of affective engagement, followed by CG and then NCG. The results from these two questionnaires are mutually consistent and, therefore, tend to confirm each other (Table 3).

Table 3. Affective engagement (interest)

\begin{tabular}{|c|c|c|c|c|c|c|}
\hline Score by Group & $\mathbf{N}$ & \multicolumn{3}{|c|}{ Mean } & SD & SE \\
\hline UCG & 37 & \multicolumn{3}{|c|}{27.568} & 6.483 & 1.0658 \\
\hline NCG & 35 & \multicolumn{3}{|c|}{21.686} & 5.723 & 0.9673 \\
\hline CG & 34 & \multicolumn{2}{|c|}{23.412} & \multicolumn{2}{|c|}{6.977} & 1.1965 \\
\hline Source of variation & SSq & \multicolumn{2}{|l|}{ DF } & MSq & $\mathbf{F}$ & p \\
\hline Between groups & 661.075 & \multicolumn{2}{|l|}{2} & 330.537 & 8.04 & 0.0006 \\
\hline Within groups & 4232.859 & \multicolumn{2}{|c|}{103} & 41.096 & & \\
\hline Total & 4893.934 & \multicolumn{2}{|c|}{105} & & & \\
\hline Contrast & \multicolumn{2}{|l|}{ Difference } & \multicolumn{2}{|l|}{ Tukey 95\% CI } & & \\
\hline UCG v NCG & 5.882 & & 2.287 to 9.476 & & & gnificant) \\
\hline UCG v CG & 4.156 & & 0.534 to 7.777 & & & gnificant) \\
\hline NCG v CG & -1.726 & & -5.397 to 1.945 & & & \\
\hline
\end{tabular}

1-way between subjects ANOVA $(n=106)$

Perceived interest during listening

\subsection{Cognitive engagement}

31 The measure of cognitive engagement presents difficulties that were alluded to earlier in this paper. It seems reasonable to say, in view of the present context, that anything defined as a cognitive process is open to some degree of interpretation. The nature of such processes when they can effectively be pinpointed makes them transient. As a result, it seems reasonable to express nothing more than a working hypothesis as far as their occurrence to any significant degree is concerned. What can be said with certitude is that some form of cognitive engagement must take place for learning to occur and the statistical analysis is a general reflection of mental trends rather than the expression of an aggregate of specifically identified activities. Once again, the learner's perception of what is happening at any particular moment during a learning activity can only be taken as an indication that something is indeed happening without really telling us to what degree it is happening. A choice $\mathrm{x}$ no choice ANOVA of the 
resulting estimation of cognitive engagement once again yielded significant effects for the unlimited-choice category: $F=7.68, p=0.0008$. Tukey comparisons confirm the statistical significance of these findings (Table 4 ).

Table 4. Cognitive engagement

\begin{tabular}{|l|l|l|l|l|}
\hline Score by Group & N & Mean & SD & SE \\
\hline UCG & 37 & 31.595 & 4.913 & 0.8077 \\
\hline NCG & 35 & 27.057 & 5.546 & 0.9375 \\
\hline ECG & 34 & 28.382 & 4.684 & 0.8033 \\
\hline
\end{tabular}

\begin{tabular}{|l|l|l|l|l|l|}
\hline Source of variation & SSq & DF & MSq & $\mathbf{F}$ & $\mathbf{p}$ \\
\hline Between groups & 393.704 & 2 & 196.852 & 7.68 & 0.0008 \\
\hline Within groups & 2638.834 & 103 & 25.620 & & \\
\hline Total & 3032.538 & 105 & & & \\
\hline
\end{tabular}

\begin{tabular}{|l|l|l|l|}
\hline Contrast & Difference & Tukey 95\% CI & \\
\hline UCG v NCG & 4.537 & 1.688 to 7.376 & (significant) \\
\hline UCG v ECG & 3.212 & 0.353 to 6.072 & (significant) \\
\hline NCG v ECG & -1.325 & -4.224 to 1.573 & \\
\hline
\end{tabular}

1-way between subjects ANOVA $(n=106)$

Cognitive engagement during listening

\section{Discussion}

This study set out to research the effect of choice on affective and cognitive engagement during L2 listening activities. As far as affective engagement is concerned, the above results are consistent with expectations in that previous comparisons of a like nature, such as those put forward by Cordova and Lepper (1996) or Hannafin and Sullivan (1996), report similar results. There are other examples, but unfortunately none of them concern choice during listening, the usual focus being either computerassisted learning or reading (for example, Schraw et al. 1998, for reading and Lepper \& Malone 1987, for CAL).

There was no marked difference between the groups with respect to desire for control ("Croyances et comportements pendant les activités d'écoute"). This might seem odd in view of underlying motivational theory that expects individuals to display a desire to control outcomes related to them. It also casts a shadow over the presumption that control 
attribution (in other words, allowing learners to choose) will have a knock-on effect on engagement. Indeed, why would a group of learners whose desire for control is to all intents and purposes no different from that of another group display greater engagement? This behaviour is in fact observed within the choice group (UCG) when it is compared to the other two groups. The implication is that some other factor is generating the increased engagement observed in the unlimited-choice group.

Notwithstanding the lack of desire for control, significant differences were revealed with respect to attitudes and interest (combining to give a measure of affective engagement) on the one hand, and cognitive engagement on the other hand. In each instance, the unlimited-choice group displayed higher levels of engagement when compared to both the limited-choice group and the control group. In accordance with the hypothesis outlined earlier, therefore, one must accept that choice has a positive impact on engagement with clear implications as regards lack of choice. This is where the present findings depart from previously established observations. If, indeed, it is not unreasonable to expect increased affective engagement, the present experimentation contradicts claims that choice has no effect on cognitive engagement. It is true that experts, particularly in motivational research (Deci 1992; Gambrell \& Marinak 1997) have argued that choice increases a number of cognitive variables like deeper processing and creativity. However, claims of this sort do not seem to be supported by experimental evidence. Other experimental research, once again that of Cordova and Lepper (1996) and Hannafin and Sullivan (1996) who ruled out choicerelated increases in cognitive engagement, as well as Pollock and Sullivan (1990) who took an extreme approach by producing evidence to the effect that autonomous learning was less effective than teacher-orchestrated learning, casts a shadow over such conclusions. Once again, none of the past research directly concerned listening in foreign-language learning or in a French context.

35 A final factor that cannot go unmentioned is the strong indication that if choice denial contributes nothing to enhancing engagement, it certainly does not seem to hamper it. A liberal interpretation of the mean scores for desire for control might imply that choice-denial increases desire for control (mean $=47.857$, against 45.000 and 45.971 for the choice-allotted and control groups respectively) while having no adverse affect on performance as reflected by the activity scores (average $=11.42-\mathrm{NCG}$, against $11.40-$ UCG and 11.35-CG). In the light of the other results, this may seem surprising. It could be put down to a phenomenon known as the Hawthorne effect, a behaviour that may be engendered by the mere fact that the participants in an experiment are aware that they are the subjects of a study or that a particular interest is being taken in them (Franke \& Kaul 1978). Alternatively, if the Hawthorne effect is not at work here, the efficacy of approaches involving choice attribution in French foreign language-learning environments may be exaggerated and in need of harsher scrutiny.

\section{Conclusion}

It has not been possible to incontrovertibly demonstrate preference for no-choice environments in the sample of learners of English taken from a population of engineering students. Taken at face value, this is in direct opposition to evidence uncovered in an earlier study (Brown 2000) in which learners of the same age group adopted a seemingly contrary attitude. Simultaneously, the strong tendency towards 
cognitive engagement contradicts experimental findings obtained in other settings. These two factors taken together are sufficient to suggest that further investigation is necessary and, indeed, has started.

The method used and the scope of the experiment are not only sound but have been tried and tested in other contexts. But clearly an as yet illusive occurrence is taking place. The fact that the experiment was conducted in a constrained setting may be a determining agent. Within the French university context, the provision of foreign language learning for students specialising in other disciplines is mandatory. Even class attendance both for foreign languages and for other subjects tends to be obligatory. Such a state of affairs may well render choice attribution meaningless - a situation referred to by Kohn (1993) as pseudo-choice. But in so far as the lot of all the students in the sample is identical, the choice allotted group must have behaved as it did for a reason or reasons which have yet to be clarified.

A final element to consider is that the importance of choice may vary according to conditions. Clifford (1991) and Stipek (1997) showed that the importance of choice grows as stakes increase. The experiment took place in a no-stakes and non-voluntary situation. That is to say, in a context where there was little to be gained or lost: the outcomes had almost no impact on things that matter to students (having fewer contact hours, spending less "out-of-class" time learning, gaining higher scores). In other words, in the absence of a clear pay-off, student attitudes towards the experiment itself, in so far as these attitudes clearly differ in other cultures, may have resulted in producing uncustomary experimental data.

The experiment continues. Two other groups, one at the school of medicine and one at the faculty of life sciences, have yet to undergo trials of a similar nature. The data yielded from these trials when compared and contrasted with the current set of data may provide further insight.

\section{BIBLIOGRAPHY}

Brown, D. N. 2002. "Of men and mice: Computer-based learning, choice and intrinsic motivation". Untele 2002: Proceedings of the $3^{\text {rd }}$ Colloquium.

Buss, D. 1990. "International preferences in selecting mates: A study of 37 cultures". Journal of Cross Cultural Psychology 21, 5-47.

Clifford, M. 1991. "Risk taking: theoretical, empirical and educational considerations". Educational Psychologist 26, 263-297.

Cordova, D. \& M. R. Lepper. 1996. "Intrinsic motivation and the process of learning: beneficial effects of contextualization, personalization, and choice". Journal of Educational Psychology 88, 715-730. 
Deci, E. L. 1992. "The relation of interest to the motivation of behavior: A self-determination theory perspective". In A. Renninger, S. Hidi \& A. Krapp (eds), The Role of Interest in Learning and Development. Hillsdale, NJ: Erlbaum, 43-70.

Deci, E. L., R. J. Vallerand, L. G. Pelletier \& R. M. Ryan 1991. “Motivation and education: The selfdetermination perspective”. Educational Psychologist 26, 325-346.

Franke, R. H. \& J. D. Kaul. 1978. “The Hawthorne experiments: first statistical interpretation”. American Sociology Review 3, 623-643.

Gambrell, L. B. \& B. A. Marinak. 1997. “Incentives and intrinsic motivation to read". In J Guthrie and A. Wigfield (eds), Reading Engagement: Motivating Readers through Integrated Instruction. Newark, DE: International Reading Association, 205-217.

Ganakumaran, S. 2006. “'Stickability' in online autonomous literature learning programmes: strategies for sustaining learner interest and motivation". Malaysian Journal of ELT Research 2, 80-96.

Hannafin, R. D. \& H. J. Sullivan. 1996. "Preferences and learner control over amount of instruction". Journal of Educational Psychology 88, 162-173.

Hofstede, G. \& M. Bond. 1984. "Hofstede's culture dimensions: An independent validation using Rokeach's Value Survey". Journal of Cross Cultural Psychology 15, 417-433.

Hynds, S. 1990. "Reading as a social event". In D. Bogdan and S. Straw (eds), Beyond Communication: Reading Comprehension and Criticism). Portsmouth, NH: Heinemann, 237-256.

Iyengar, S. S. \& M. R. Lepper. 1999. "Rethinking the value of choice: A cultural Perspective on intrinsic motivation”. Journal of Personality and Social Psychology 76, 349-366.

Kohn, A. 1993. "Why and how to let students decide". Phi Delta Kappan September Issue, 8-20.

Lepper, M. R. \& T. W. Malone. 1987. "Intrinsic motivation and instructional effectiveness in computer-based education.” In R. E. Snow \& M. J. Farr (eds), Aptitude, Learning and Instruction: Vol 3 Conative and Affective Process Analysis. Hillsdale, NJ: Erlbaum, 255-286.

Lieury, A. \& F. Fenouillet. 1997. Motivation et réussite scolaire. Paris: Dunod.

Liu, J. 2005. "The mode of promoting learner autonomy for non-English majors through classroom instruction". US-China Education Review 2, 46-52.

Maynard, J. 2003. "Synchronous computer-mediated communication and learner autonomy in female Emirati learners of English". Unpublished doctoral dissertation, University of Exeter (England).

Miserandino, M. (1996). "Children who do well in school: Individual differences in perceived competence and autonomy in above-average children". Journal of Educational Psychology 88, 203-214.

Pettigrew, T. F. 1988. "Integration and pluralism". In P. A. Katz \& D. A. Taylor (eds), Eliminating Racism: Profiles in Controversy. New York: Plenum, 19-52.

Pollock, J. C. \& H. J. Sullivan. 1990. "Practice mode and learner control in computer-based instruction". Contemporary Educational Psychology 15, 251-260.

Richardson, P. 2004. "Possible influences of Arab-Islamic culture on the reflective practices proposed for an education degree at the Higher Colleges of Technology in the United Arab Emirates". International Journal of Educational Developement 24, 429-436. 
Schraw, G., T. Flowerday \& M. F. Reisetter. 1998. “The role of choice in reader engagement”. Journal of Educational Psychology 90, 705-714.

Stipek, D. J. 1997. “Motivation and instruction.” In D. C. Berliner \& R. C. Calfee (eds), Handbook of Educational Psychology. New York: Macmillan, 85-113.

Triandis, H. C. 1990. "Cross-Cultural Studies of Individualism and Collectivism". In J. J. Berman (ed), Cross Cultural Perspectives: The Nebraska Symposium on Motivation 1989. Lincoln: University of Nebraska Press, 41-133.

Triandis, H. C. et alii. 1986. "The measurement of the etic aspects of individualism and collectivism across cultures". Australian Journal of Psychology 38, 257-267.

Wise, S. L. 1994. "Understanding self-adapted testing: The perceived control hypothesis". Applied Measurement in Education 7, 15-24.

Zimmerman, B. 1990. "Self-regulated learning and academic achievement: An overview". Educational Psychologist 25, 3-17.

\section{APPENDIXES}

\section{Appendix 1}

\section{Choisir son activité d'écoute en mode test}

Les trois descriptifs ci-dessous correspondent à une activité de compréhension orale. Choisissez l'écoute que vous aimeriez rencontrer si, par exemple, vous vous trouviez en situation de test ou de contrôle continu.

Les thèmes sont les suivants :

A Une écoute appartenant au domaine de la littérature qui dépeint, parfois de façon humoristique, la vie des Amish aux États-Unis.

B Une écoute appartenant au domaine des sciences de l'ingénieur qui relate brièvement l'histoire de la construction des ponts.

C Une écoute appartenant au domaine des actualités qui traite du rôle des universités dans le futur. 


\section{\begin{tabular}{|l|l|l|l|l|l|}
\hline$A$ & $B$ & $C$ & $D$ & $E$ & $F$ \\
\hline
\end{tabular}}

Croyances et comportements face aux devoirs et tests

\section{Questionnaire}

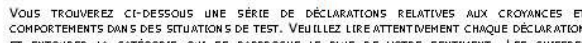

ET ENTOURER LA CATEBORIE QUT SE RAPPROCHE LE PLUS DE WTTRE SENTTMENT. LES CHITFRES

\section{$1=$ jamais
$2=$ peu}

$2=$ peu
$3=$ quelquefois
$4=$ souvent

$5=$ toujours
$5=$ souvent

1. J'aimerais avoir mon mot à dire au
sujet des dates de la programmation $\quad \begin{array}{lllll}1 & 2 & 3 & 4 & 5\end{array}$

2. Pendant un tetst / d devoli, f'almerals
pouvoir répondre aux questions dans

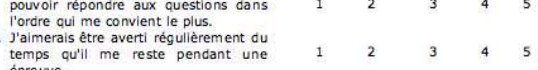

epreave.
J'aimerais pouvoir cholisir de repasser

$\begin{array}{llllll}\text { J'aimerais pouvoir choisir le format de } \\ \text { mon test (rédaction sur feulliles libres, } & 1 & 2 & 3 & 4 & 5\end{array}$

QCM, informatisé, oral, etc.).

$\begin{aligned} & \text { J'aimerais pouvoir opter entre faire un } \\ & \text { devoir a la maison ou en classe. }\end{aligned}$
1

$\begin{array}{llllll}\text { J'aimerais savoir o' } \text { 'avance } \text { le format } & 1 & 2 & 3 & 4 & 5\end{array}$

des exercices qui, composent un test
(QCM, rédaction, etc.).
Lorsque je ne sais pas immé diatement

Lorsque je ne sais pas immédilatement
comment répononere à une question

pendant un test ou devoir, je ressens
in sentiment de stress ou de panique.

II est dans ma nature d'aspirer ver

Sil je ne parvenais pas à donner
une réponse à tous les exercices;

toutes les questions d'un devoir ou
d'un test, cela me dérangerait
beauccoup.

beaucoup.
J'aimerais connaitre le nombre de

points accordés à a chaque exercice
d'un test / devolir.

12. Une démarche importante pou

mol consiste à m'encourager en
disant que faural un bon résultat.

13.
maximum de maititise pendant un test

dans lequel je réponds, le format ou

Appendix 2b

\section{\begin{tabular}{|l|l|l|l|l|l|}
\hline$A$ & $B$ & $C$ & $D$ & $E$ & $F$ \\
\hline
\end{tabular}}

L'intérêt perçu pendant les activités d'écoute

Questionnaire

Vous trouverez ci-dessous une série de déclarations relatives au degre d'intérêt que vous avez manileste pendant lactivité drecoute que vous venez de faire. Veuiliez lire attentivement chaque déclaration et entourer le chiffre qui se rapproche le plus de votre sentiment. Les

$1=$ pas du tout d'accord
$5=$ tout à fait d'accord

1. L'écoute que j'ai choisie était plutôt intéressante.

2. J'aimerais dans un avenir très proche comparer et discuter mes réponses av
mon groupe. 3. Si j'en avais la possibilité,
j'écouterais le passage de nouveau
pour mieux le comprendre. pour mieux le comprendre.

4. Je me suis immergé dans l'écoute

5. Je continuerais à réfléchir pendant ins ou moins longtemps aux
informations contenues dans le passage et a leurs implications. . Le thème de écoute que jai chois

7. Je pense que d'autres étudiants que j'ai choisie.

Jaimerais travaille (écouter ou même lire) davantage Le passage que j'ai choisi était l'une des écoutes les plus intéressantes que j'ai rencontrées en cours d'anglais.

10. J'étais vraiment absorbé dans

1.

d'écoute illimité, le thè un choix j'aurais choisi eût été celui de (un seul thème)

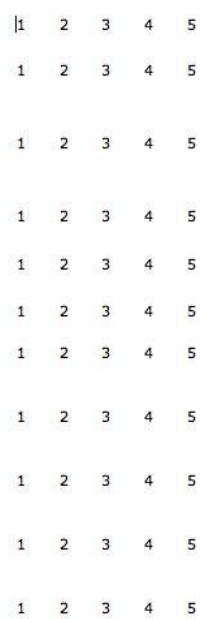




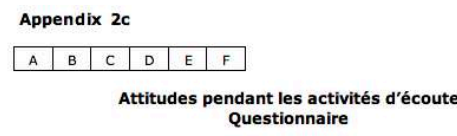

Vous trouverez ci-dessous une série de déclarations relatives aux

d'écoute que vous venez de faire. Veuillez lire attentivement chaque

déclaration et entourer le chiffre qui se rapproche le plus de votre

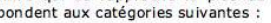

$1=$ pas du tout d'accord
$5=$ tout à fait d'accord

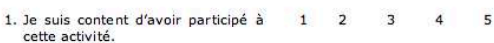

2. Je suis satisfait du choix d'écoute. $1 \begin{array}{lllll}1 & 2 & 3 & 4 & 5\end{array}$

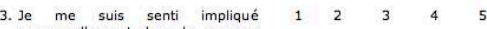

personnellement dans le passage
que j'ai écouté.

4. J'ai fait de mon mieux pour
comprendre le passage et
répondre avec exactitude aux

5. Je me suis senti lié $\begin{array}{llllll}\text { personnellement } & 2 & 3 & 4\end{array}$

(émotionnellement) au thème du

6. J'ai apprécié la nature du travail

que nous avons fait pendan
lactivité.

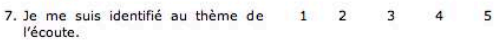

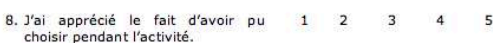

9. J'ai compris les implications $\begin{array}{llllll}1 & 2 & 3 & 4 & 5\end{array}$

10. Ce travail était très motivant. $\begin{array}{llllll}1 & 2 & 3 & 4 & 5\end{array}$

11. Pendant l'activité, je pense
que l'on a pris en considération
mon point de vue.

12. Pendant l'activité, j'avais
limpression de pouvoir contrôler
la situation.

Appendix 2d

\begin{tabular}{|l|l|l|l|l|l|}
\hline A & B & C & D & E & F \\
\hline
\end{tabular}

Engagement cognitif pendant les activités d'écoute Questionnaire

Vous trouverez ci-dessous une série de déclarations relatives au degré

d'engagement que vous avez peut-être manifesté pendant l'activité déclaration et entourer le chiffre qui se rapproche le plus de votre sentiment. Les chiffres correspondent aux catégories suivantes :

$1=$ pas du tout d'accord
$5=$ tout à fait d'accord

1. Pendant l'activité, je pense m'être
livré à l'interprétation de certaines livré à l'interprétation de certaines
informations contenues dans

'écoute.

2. J'ai effectué des traductions
mentales de passages plus ou courts pendant l'écoute.

3. J'ai effectué des traductions
mentales de certaines parties de

.

4. J'ai douté de certaines des
informations contenues dans le information
passage.

5. J'aurais voulu que certaines
parties de l'écoute soient
davantage développées.

6. L'activité m'a permis d'apprendre

expressions inconnues.

7. L'activité m'a permis d'améliorer oral.

8. Après réflexion, je me rends
compte que j'ai mal interprété compte que $j$ ai mal interpré
certaines informations dans

9. Je pense que la diction était de
bonne qualité.

10. Je pense que le texte que $j^{\prime}$ '
entendu était bien rédigé.

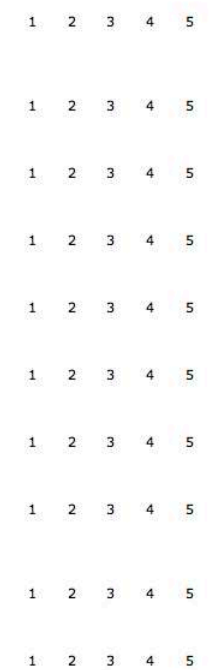

NOTES

1. Freedom is the right to choose: the right to create for oneself the alternatives of choice. Without the possibility of choice, and the exercise of choice, a man is not a man but a member, an 
instrument, a thing - sometimes attributed to Thomas Jefferson (1743-1826) but more likely said by Archibald MacLeish (1892-1982).

2. Data from the two other studies will be discussed and compared in a later paper.

\section{ABSTRACTS}

The notion of choice has been characterised as one of the regulating agents of intrinsic motivation. A study being carried out at the Université H. Poincaré is investigating the effect of choice on cognitive and affective engagement during listening tasks. The study compares two groups of English language learners specialising in other disciplines. The aim of the study is to attempt to clarify whether "unrestricted" choice genuinely enhances positive affective perceptions of the listening experience compared to denied-choice and control groups. A further question concerns cognitive engagement and whether any increase in favourable affective perceptions automatically leads to heightened cognitive engagement. This on-going study examines and provides insight into behaviour that may be typical of choice / no-choice learners in the field of engineering sciences. The paper situates the French L2 motivational context with respect to the Anglo-Saxon L2 motivational context on which the vast majority of current motivational theory is based. Relying on data gathered during this and previous studies, the paper argues that conclusions about motivation drawn from dimensions of Anglo-Saxon culture and learning tradition cannot always be automatically transferred to the French L2 context.

La notion de choix a été définie comme étant l'un des éléments qui régulent la motivation intrinsèque. Une étude en cours à l'Université H. Poincaré tente de cerner l'impact que peut avoir le choix de l'apprenant sur l'engagement cognitif et affectif pendant les activités d'écoute. L'étude compare deux groupes d'apprenants en anglais pour spécialistes d'autres disciplines. L'objet de l'étude est d'établir si un choix ouvert pour l'activité d'écoute améliore réellement les perceptions affectives de l'expérience d'écoute lorsque ces perceptions sont comparées à celles de deux autres groupes, un groupe avec un choix limité et un groupe de contrôle. Une seconde question est de savoir si l'engagement cognitif augmente automatiquement lorsque les perceptions affectives positives s'intensifient. Cette étude fournit un aperçu du comportement qui pourrait être typique d'étudiants en sciences de l'ingénieur apprenant dans des contextes de choix/non choix. Cet article situe le contexte motivationnel en apprentissage des langues en France par rapport au contexte anglo-saxon qui conditionne la grande majorité de la théorie motivationnelle actuelle. Prenant appui sur des données rassemblées pendant plusieurs études, l'auteur avance que les conclusions fondées sur la culture et la tradition d'apprentissage anglosaxonnes ne peuvent pas s'appliquer automatiquement au contexte français d'apprentissage des langues.

\section{INDEX}

Mots-clés: écoute, engagement, motivation, perception

Keywords: engagement, listening, motivation, perception 


\section{AUTHOR}

\section{DAVID N. BROWN}

David N. Brown is a Senior Lecturer at the École Supérieure des Sciences et Technologies de l'Ingénieur de Nancy (ESSTIN), Université Henri Poincaré in Nancy, where he heads the Department of Foreign Languages and Communication. His main research interest is L2 motivation, including language learner beliefs, attitudes and perceptions. He also takes an interest in ESP and technology-driven language learning. david.brown@esstin.uhp-nancy.fr 